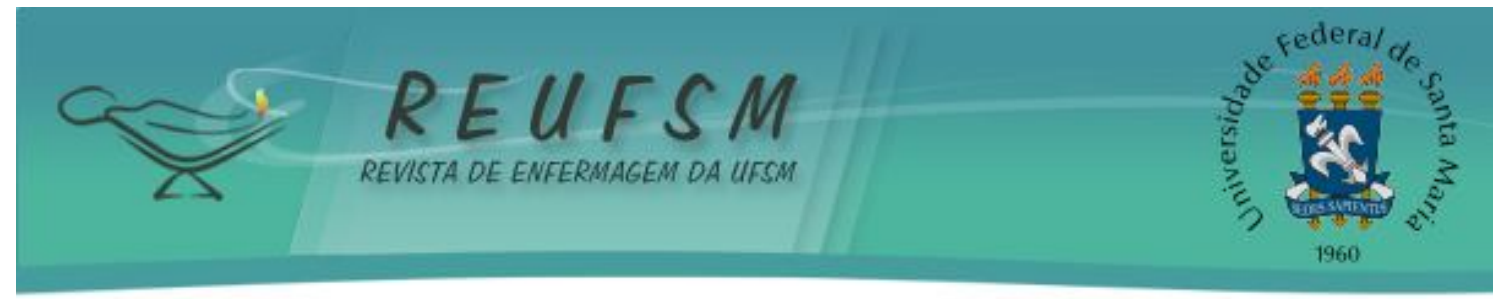

ARTIGO ORIGINAL

\title{
ADOLESCER DE CRIANÇAS INFECTADAS POR TRANSMISSÃO VERTICAL DO HIV: IMPLICAÇÕES PARA O CUIDADO DE ENFERMAGEM
}

\author{
BECOMING A TEENAGER IN CHILDREN INFECTED THROUGH HIV VERTICAL \\ TRANSMISSION: IMPLICATIONS OFR NURSING CARE
}

\section{EL CRECER DE NIÑOS INFECT ADOS POR TRANSMISIÓN VERTICAL DEL VIH: IMPLICACIONES PARA EL CUIDADO DE ENFERMERÍA}

\author{
Thaís Silva de Souza ${ }^{1}$ \\ Ivone Evangelista Cabral ${ }^{2}$ \\ Cristiane Cardoso de Paula ${ }^{3}$
}

\begin{abstract}
RESUMO: Objetivo: descrever as demandas sociais e de saúde das crianças que têm HIV/ AIDS por transmissão vertical na transição da infância para a adolescência. Método: pesquisa com abordagem qualitativa de natureza descritiva, aprovada em Comitê de Ética (096/ 06-EEAN/ UFRJ ; 09/ 07-IPPMG/ UFRJ; 36/07-HUGG/ UNIRIO). As informações foram obtidas por meio de entrevista, com 11 crianças, entre 12-14 anos, que conheciam 0 diagnóstico. Foi desenvolvida análise de conteúdo temática. Resultados: foram identificadas as demandas sociais do adolescer: relacionamentos, atividades, convivência escolar, namoro; e as demandas de saúde do adoecer: revelação do diagnóstico, seguimento hospitalar, tratamento medicamentoso, preconceito, futuro. Conclusão: Diante do adolescer, a teoria psico-social do desenvolvimento de Erikson mostrou-se coerente às demandas sociais, porém não contempla as demandas da necessidade especial de saúde dessas crianças. 0 cuidado à saúde precisa contemplar o acompanhamento das crianças e suas famílias durante 0 desenvolvimento puberal e 0 processo de adoecimento. Descritores: Saúde do adolescente; Saúde da criança; Enfermagem pediátrica; Síndrome de Imunodeficiência Adquirida.
\end{abstract}

ABSTRACT: Objective: to describe social and health demands of children who has HIV/ AIDS through vertical transmission on the transition from childhood to adolescence. Method: qualitative research with descriptive approach, approved by Ethics Committee (096/ 06-EEAN/ UFRJ ; 09/ 07-IPPMG/ UFRJ ; 36/ 07-HUGG/ UNIRIO). Information was obtained through interview with 11 children, aged between 12-14 years old, that knew their diagnosis. It was developed thematic content analysis. Results: social demands of becoming a teenager were identified: relationships, activities, scholar acquaintanceship, dating; and ill health demands: disclosure, hospital follow-up, medical treatment, prejudice, future. Conclusion: Face becoming a teenager, Erikson's psycho-social development theory, is coherent to social demands, but it doesn't address these children's special health needs. Health care needs to include children and their families monitoring during the pubertal development and the disease process.

Descriptors: Adolescent health; Child health; Pediatric nursing; Acquired immunodeficiency Syndrome.

\footnotetext{
1 Enfermeira. Residência em saúde pública (UNIRIO/RJ/BR). Servidor publico no IFF/FIOCRUZ. thais407@hotmail.com

2 Enfermeira. Doutora em enfermagem (EEAN/UFRJ/RJ/BR). Programa de estágio pós-doutoral na Division of social and transcultural psychiatry, Mcgill University, Montreal. Canadá. Professora associado no Departamento Materno Infantil da Escola de Enfermagem Anna Nery da Universidade Federal do Rio de Janeiro. icabral@superig.com.br

3 Enfermeira. Doutora em enfermagem (EEAN/UFRJ/RJ/BR). Professor adjunto no Departamento de Enfermagem da Universidade Federal de Santa Maria (UFSM/RS/BR). cris_depaula1@hotmail.com
} 


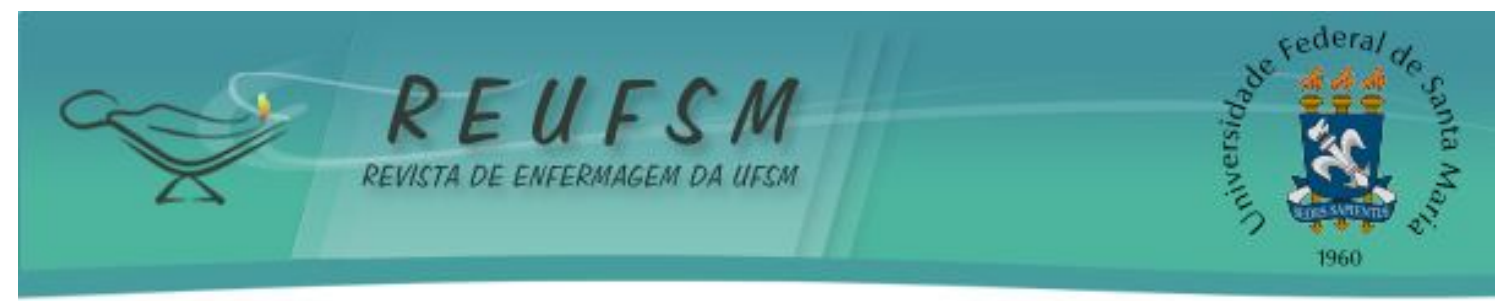

RESUMEN: Objetivo: describir las demandas sociales y de salud de los niños que tienen VIH/SIDA por transmisión vertical en la transición de la infancia para la adolescencia. Método: investigación con abordaje cualitativo de naturaleza descriptiva, aprobada en Comité de Ética (096/06-EEAN/ UFRJ; 09/07-IPPMG/UFRJ; 36/07-HUGG/ UNIRIO). Las informaciones fueron obtenidas a través de entrevista, con 11 niños, entre 12 - 14 años, que conocían el diagnóstico. Fue desarrollado análisis de contenido temático. Resultados: fueron identificadas las demandas sociales del crecer de los adolescentes: relacionamientos, actividades, convivencia escolar, noviazgo; y las demandas de salud del enfermedad: revelación del diagnóstico, seguimiento hospitalario, tratamiento medicamentoso, prejuicio, futuro. Conclusión: Delante del crecer de adolescente, la teoría psicosocial del desarrollo de Erikson se mostró coherente a las demandas sociales, sin embargo no contempla las demandas de la necesidad especial de salud de esos niños. El cuidado a la salud necesita contemplar el acompañamiento de los niños y sus familias durante el desarrollo puberal y el proceso de enfermedad.

Descriptores: Salud del adolescente; salud del niño; Enfermería pediátrica; Síndrome de Inmunodeficiencia Adquirida.

\section{INTRODUÇÃO}

Com o investimento crescente para dar conta do agente etiológico da Síndrome da Imunodeficiência Adquirida (AIDS), na busca da garantia da sobrevivência, um grupo de crianças com AIDS por transmissão vertical não morreu. Venceu a etapa da infância adentrando em uma nova fase do desenvolvimento humano. Esse grupo é conhecido como a primeira geração que nasceu infectada pelo Vírus da Imunodeficiência Humana (HIV) e está adolescendo. ${ }^{1-5}$

Esse novo grupo apresenta demanda de necessidade especial de saúde das crianças que tem AIDS, qual seja: a dependência da tecnologia medicamentosa. Portanto, são inseridas no grupo de crianças com necessidades especiais de saúde (CRIANES), as quais requerem: uso contínuo de medicamentos para sobreviver; serviços de suporte emocional/ comportamental, com limitações de atividades; elevada frequência a unidade de saúde; acompanhamento por vários profissionais de saúde de diferentes especialidades; expertise no cuidado profissional e familial; e, no cuidado familial, educação em saúde de forma contínua. ${ }^{6-8}$

Essa necessidade especial de saúde determina desafios do cuidar para a família, dentre os quais se destacam a necessidade de: reorganização familiar, desvendar do corpo cognoscível da criança; apropriar-se de novos saberes e práticas de cuidar; incorporar novas tecnologias ao processo de cuidar; ampliar a rede social da família na atenção à criança; apoio do Estado no provimento de recursos de manutenção da vida com qualidade. ${ }^{6-8}$

No entanto, observa-se que o foco da atenção à saúde está direcionado mais à clínica do adoecimento do que, propriamente, à criança que tem HIV/ AIDS. Diante disso, se destaca a questão norteadora: como está sendo o processo de desenvolvimento e de adoecimento na transição da infância para a adolescência para àqueles que têm HIV/AIDS. Justifica-se o desenvolvimento dessa pesquisa pautado também na relevância da pluralidade das pessoas que têm AIDS; no entanto, parece que a sua singularidade adquire menos visibilidade no conjunto das investigações que privilegiam as questões clínico-epidemiológicas. 0 modo de cada ser vivenciar desafios, medos e dificuldades/facilidades no dia-a-dia perde relevância no confronto com as questões da pluralidade. A adesão à terapêutica medicamentosa e outras questões dos cuidados de saúde são dependentes da compreensão que cada um confere ao seu viver. Assim, o objetivo foi descrever as demandas sociais e de saúde do grupo de crianças que tem AIDS, infectadas por transmissão vertical do HIV, durante a transição da infância para a adolescência. 


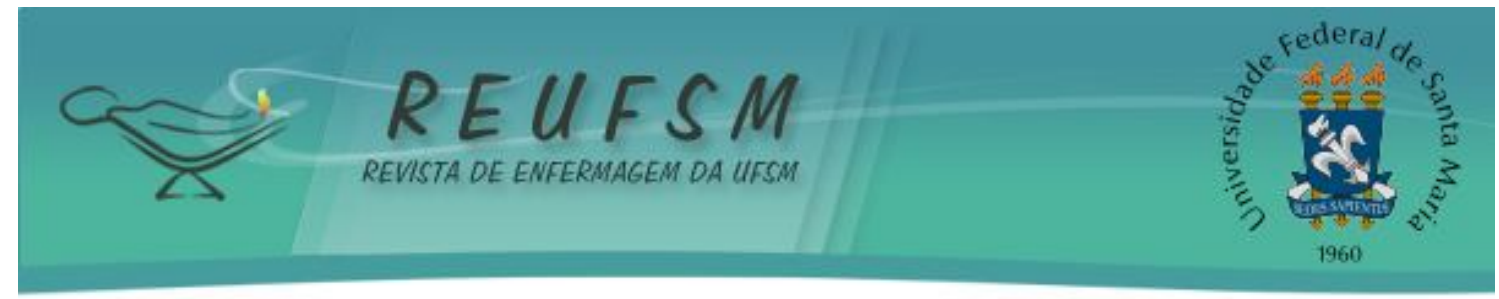

MÉTODO

Pesquisa qualitativa, com abordagem descritiva. Teve como sujeitos da pesquisa 11 meninos/as infectados por transmissão vertical do HIV. Os critérios de inclusão foram: faixa etária de 12-14 anos; conhecer o seu diagnóstico, não estarem institucionalizados. Dos 11 sujeitos, dois eram órfãos maternos, um órfão paterno e três órfãos paternos e maternos, sendo que esses seis depoentes eram cuidados por membros da família consanguínea de primeiro grau. O número de suj eitos não foi determinado previamente, visto que a etapa de campo mostrou o quantitativo de entrevistas necessárias para responder ao objetivo da pesquisa. ${ }^{9}$

O cenário da pesquisa contemplou três hospitais universitários, que são serviços de referência para atendimento de crianças que têm HIV/AIDS no Rio de J aneiro. A etapa de campo foi desenvolvida de fevereiro a setembro de 2007, após aprovação e autorização dos Comitês de Ética em Pesquisa (protocolos EEAN/ UFRJ 096/06; IPPMG/ UFRJ 09/ 07; HUGG/UNIRIO 36/07). Os familiares assinaram o termo de consentimento livre e esclarecido e os 11 meninos/ as assinaram o termo de assentimento.

Para produção dos dados empíricos foi utilizada a entrevista. A questão norteadora foi: conte-me como está sendo virar adolescente? A questão "como é o seu diaa-dia tendo essa doença?" foi mencionada, somente, quando o depoente falava da sua condição sorológica. Utilizou-se a palavra doença, pois a AIDS foi mencionada dessa forma nas entrevistas, sendo referendada, mas não nominada.

Desenvolveu-se a análise do material empírico segundo a análise de conteúdo temática ${ }^{10}$, em três etapas: pré-analise; exploração do material e interpretação dos resultados.

A pré-analise foi desenvolvida através da leitura flutuante do material empírico na íntegra. Nesse movimento de escuta e leituras, primeiramente, buscou-se entender o universo em que viviam as crianças. Posteriormente, como estava sendo chegar à adolescência e ter AIDS.

A exploração do material se deu pela composição dos resultados da pesquisa, a partir da codificação cromática de fragmentos dos depoimentos, que responderam ao objetivo. Destacou-se em: azul o que as crianças falaram acerca do processo de desenvolvimento; e em vermelho 0 que as crianças falaram acerca do processo saúde-doença. Para selecionar os fragmentos empíricos e estruturar os núcleos temáticos, foi preciso atenção para compreender o sentido da comunicação, atingindo, através de significados ou significantes, outros significados, que estão relacionados à questões políticas, psicológicas, sociológicas. ${ }^{11-12}$

A interpretação dos resultados foi desenvolvida por meio da estruturação do material empírico nos núcleos temáticos: 1) o processo de adolescer (o que elas disseram sobre o processo de desenvolvimento); 2) o processo de adoecer (o que elas disseram sobre o processo saúde-doença). Na discussão, a partir da Teoria psico-social do desenvolvimento humano de Erikson ${ }^{11-12}$, emergiram os sub-núcleos temáticos que compuseram a descrição dos resultados e encaminharam à discussão.

\section{RESULTADOS E DISCUSSÃO}

Para descrição do processo de desenvolvimento e adoecimento, buscou-se como as crianças que têm AIDS, por transmissão vertical do HIV, apresentam suas necessidades, diante do: PROCESSO DE DESENVOLVIMENTO humano, por estar adolescendo; e do PROCESSO SAÚDE/ DOENÇA por ter AIDS. Para tanto, os núcleos e sub-núcleos temáticos são apresentados, a seguir: 


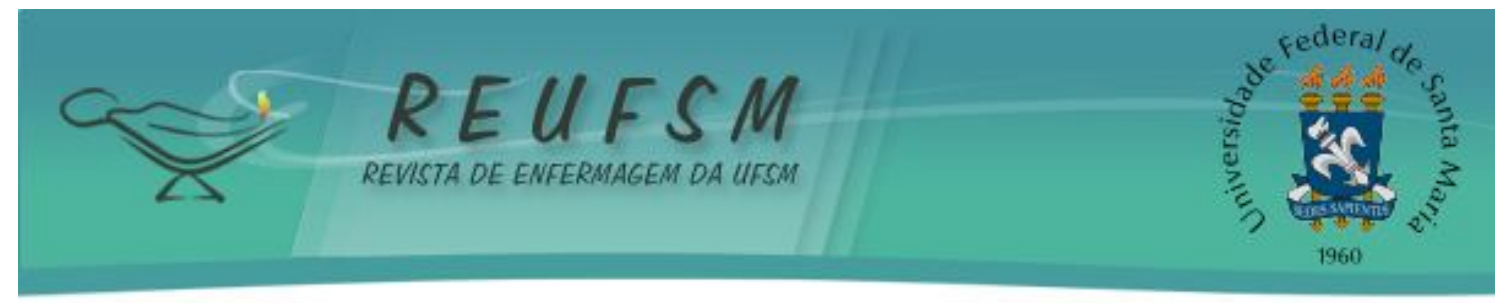

\begin{tabular}{|c|c|}
\hline NÚCLEOS TEMÁTICOS & SUB-NÚCLEOS TEMÁTICOS \\
\hline Demandas sociais do adolescer & $\begin{array}{l}\text { como se sentem virando adolescentes } \\
\text { relacionamentos } \\
\text { atividades do dia-a-dia } \\
\text { convivência escolar } \\
\text { namoro }\end{array}$ \\
\hline Demandas de saúde do adoecer & $\begin{array}{l}\text { como se sentem tendo a doença } \\
\text { revelação do diagnóstico } \\
\text { seguimento hospitalar } \\
\text { tratamento medicamentoso } \\
\text { preconceito } \\
\text { futuro }\end{array}$ \\
\hline
\end{tabular}

\section{As demandas sociais do adolescer}

Os adolescentes referiram que se sentem como seus pares, tendo responsabilidades sobre seus atos e liberdade para fazer escolhas. Não podem mais fazer as coisas que faziam enquanto eram crianças. Muitos gostam dessa fase e alguns sentem falta das brincadeiras.

às vezes, eu acho bom (virar adolescente), às vezes, eu acho chato. É legal e chato junto. [pausa na fala] Porque vai perdendo a infância, as brincadeiras, tem que ter mais responsabilidades, tem que ter mais juízo também, na escola, na família. Então são várias coisas. E ser criança é bom, porque pode fazer qualquer coisa que ninguém liga, agora adolescente não, quando eu faço alguma coisa já vem toda a culpa para cima. [...] Por um lado é chato, mas por outro não, porque agora eu posso sair mais sozinha, fazer as minhas coisas, posso fazer isso, posso fazer aquilo, mas sempre com a autorização dos pais. (C7)

O que apresentam ou sentem nessa fase está relacionado com as experiências vividas. ${ }^{11}$ Precisam de referências para seus comportamentos, destacando-se a necessidade de aceitação e de reconhecimento social, a partir de uma "visão ideológica de uma sociedade que afeta mais claramente 0 adol escente ansioso por se afirmar perante seus iguais". 12:242

Ora gostam de estar crescendo, ora sentem as perdas da infância. "A confusão no sentimento de identidade levam os adolescentes não só se ajudarem temporariamente uns aos outros, mas também a vencer muitas dificuldades, através da formação de grupinhos". .2:241 $^{2}$

As pessoas que participam de sua vida, nessa fase de transição para a adolescência, são, principalmente, a família e os colegas da escola. Isso acontece em diferentes cenários, como: igrejas, Ian houses, e outros locais de lazer.

a minha mãe é a minha família [...] a minha mãe me ajuda, faz isso, faz aquilo, porque amanha eu é que vou estar ajudando ela [...] eu tenho um irmão por parte de pai [...] eu ficava com a minha vó [...] eu tenho meus amigos [...] tem amigos bons, que querem o bem, e tem amigos que só pensam em se divertir [...] eu comecei a andar com uma menina que era bem rebelde, aí eu comecei a ficar rebelde com a minha mãe que nem ela. Mas não fiz nada de grande assim, de ruim. (C9) 


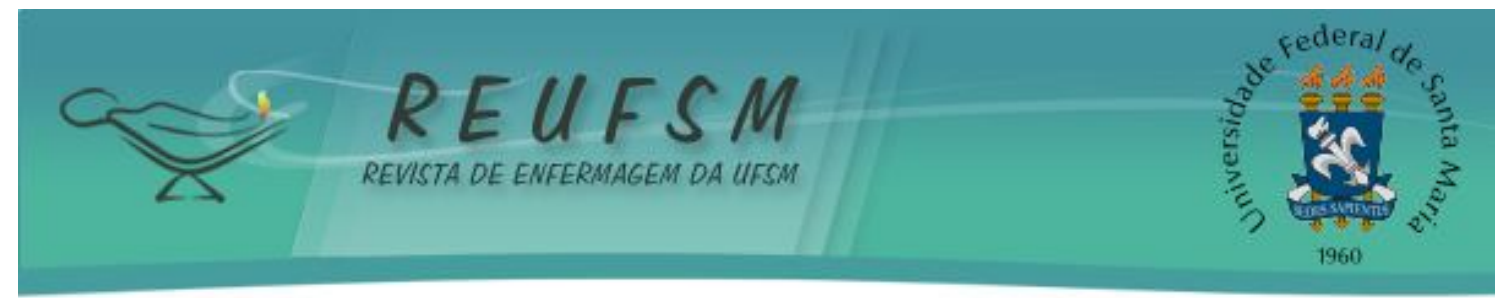

Esse processo se denomina como ritualização, no qual o adolescente busca interagir com os iguais, formando pequenos grupos de convívio. Isso acontece através da participação em eventos sociais que envolvem diferentes atividades de esporte, shows musicais, arenas políticas ou religiosas. ${ }^{11}$

Percebem que suas responsabilidades aumentam, então no dia-a-dia precisam cumprir atividades escolares e domésticas. Fazem os deveres da escola e ajudam em casa, lavando louça, roupa, cuidando dos irmãos mais novos, fazendo comida. Mas tem atividades de lazer como brincar, assistir televisão, ouvir música.

Eu vou pra escola e quando volto eu fico em casa, vendo televisão [... ] vou na lan house e não tenho mais nada para fazer. [...] quando chega final de semana às vezes eu saio e outras não, tipo quando tem festa ou quando tem al guma coisa boa no clube, muitas vezes eu não saio não. (C10)

A criança desenvolve, gradualmente, um senso de responsabilidade moral, que lhe possibilita adquirir compreensão das funções e dos papéis sociais. Nesse momento do desenvolvimento humano, a criança mostra-se com vontade de aprender e participar, evidenciando sua capacidade e aptidão para desenvolver-se em cooperação. ${ }^{12}$

A escola é o cenário de aprendizado, no qual se relacionam com os pares e desenvolvem atividades de lazer. As crianças referem que mesmo quando não gostam de estudar, adoram a escola, pelo que Ihes proporciona.

na escola, converso com os meus amigos, depois vou para sala de aula, a gente corrige os deveres de casa com a professora, depois ela dá os deveres de aula, aí tem lanche, depois mais deveres de aula, a gente tem física, matemática, inglês, artes e outras matérias. (C4)

A etapa escolar é de extrema importância para a criança em transição para a adolescência, pois é quando desenvolve o juízo de respeito para com os outros, visto que as diferenças aparecem e as crianças precisam aprender a conviver entre elas. ${ }^{12}$

Algumas crianças associam a chegada da adolescência como o momento em que podem namorar. Preocupam-se em saber beijar, sem pensar em relacionamentos duradouros. Outras não pensam ainda nisso, pois se consideram muito novas.

virar adolescente, é assim uma época de... [pausa na fala] de namoro, né?! (C2)

Na busca pelo senso de identidade, as crianças podem se apresentar ansiosas e dispostas a compartilhar sua identidade e intimidade. Entre os pares, amizade permeada pela descoberta da sexualidade possibilita que meninos e meninas revelem-se complementares em suas relações. A construção desses relacionamentos, também, se configura como uma tentativa de definição de sua identidade, por meio da qual projeta sua imagem em outra pessoa, para então vê-la refletida e gradualmente definida. ${ }^{12}$

\section{As demandas de saúde do adoecer}

A revelação acontece entre a criança e seu familiar, podendo ter a participação de um profissional da saúde. No entanto, mesmo antes de os familiares revelarem, as crianças dizem que já desconfiavam/sabiam qual era a sua doença, pois já ouviram falar na escola ou no serviço de saúde. 


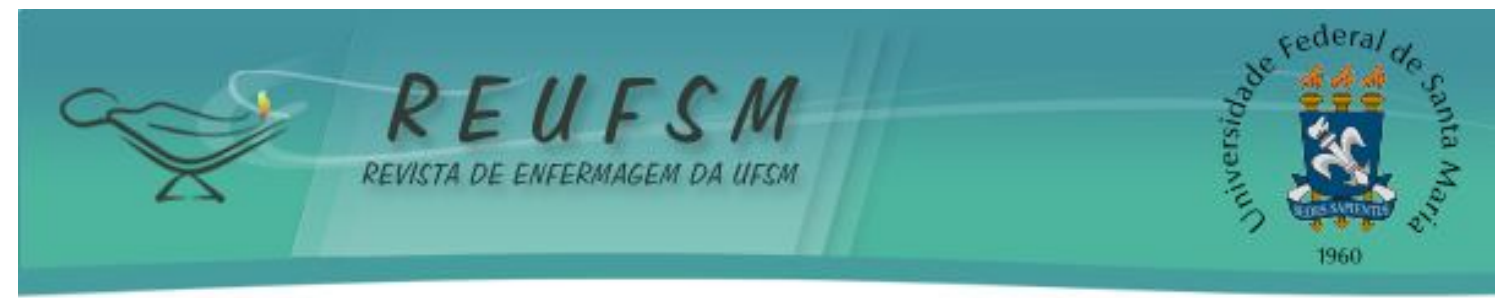

Para alguns adolescentes a doença gerou tristeza, vergonha, revolta e dificuldades de aceitação de seu diagnóstico. Apesar de sentirem-se normal, consideram "chato" ter essa doença e não gostam de falar sobre 0 assunto.

Meu problema não é, assim, mini, mas não vamos exagerar. Eu, também, sei controlar [...] não é uma coisa, assim, ruim, porque se fosse uma coisa, assim, ruim eu já estaria em cima da cama chorando que nem uma margarida [...] eu tento viver a vida da melhor maneira possível e eu sou muito feliz! [...] eu tinha vergonha que eu tinha HIV, eu me achava diferente das outras pessoas [...] eu consegui perceber que eu não era diferente de ninguém, mas não era igual a todo mundo, porque ninguém é igual, para mim, eu não sou igual a ninguém. (C3)

A doença resulta em diferentes repercussões na vida das crianças: o questionamento sobre sua condição de saúde, a capacidade de compreender seu diagnóstico, a manutenção do tratamento, entre outras. Uma preocupação dos familiares quanto à revelação é se a criança/ adolescente manterá o segredo/ silêncio, sem contar para seus amigos.

depois que eu fiquei sabendo, quando eu tinha 11 anos que minha tia me contou, me contou que eu tinha esse problema [silêncio] assim [pausa na fala] eu também não aceitava [silêncio] [...] minha tia depois conversou com a minha professora, e a professora foi dando mais apoio também, [silêncio] foi bem uma paulada assim. (C2)

O hospital é cenário de tratamento/ cuidado, onde frequentam desde pequenos. $\mathrm{Na}$ infância foram levados por familiares, mas nessa etapa do desenvolvimento vão sozinhos. Sabem que têm que ir às consultas para acompanhar sua imunidade, carga viral e os efeitos dos remédios. Consideram que são bem atendidos, e têm a possibilidade de conhecer e se relacionar com outras crianças infectadas.

Eu venho aqui no hospital também. Aqui também é legal, que tem gente para orientar sabe? Como viver na vida, como se cuidar bem [pausa na fala] aprende que quando for fazer relação sexual tem que usar camisinha [... Eu venho aqui desde que eu nasci. (C6)

0 cotidiano medicamentoso é difícil, pois tem que tomar muitos remédios, em diversos horários e todos os dias. Sabem que o tratamento é importante para sua saúde, mas têm dificuldades com o tamanho, gosto dos comprimidos e com os horários, pois interferem no seu dia-a-dia. Então, algumas crianças pararam de tomar, outras tomam sozinhas ou precisam da ajuda de familiares para lembrar os horários.

Eu também tomo remédio [pausa na fala] sete horas da manhã, sete horas da noite e um antes de dormir [pausa na fala] eu mesmo que tomo [pausa na fala] é chato, mas tem que tomar [...] para evitar pegar alguma coisa assim, sempre ficar imunizado. (C5)

O silêncio em relação à doença fica evidente, pois a maioria das crianças sequer a nomina, e poucas pessoas sabem do diagnóstico e não falam sobre isso. Isso acontece pelo 


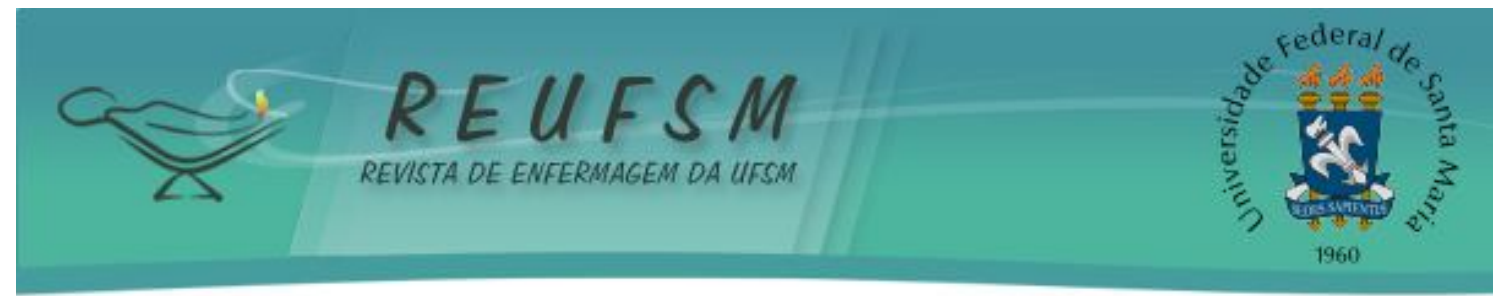

preconceito relacionado à AIDS, em que o silêncio configura-se como um forma de proteção contra o preconceito social.

Meus irmãos também sabem. Meu padrasto também tem, e minha avó, meu tio e minha tia também sabem que eu tenho. E a gente não fica falando disso, para que? Eu não conto para ninguém. [silêncio] Meus amigos não sabem, e nem na escola. Para que contar? Não gosto [...] não preciso ficar falando para os outros, na minha família é que sabem, só! (C10)

No que se refere ao futuro, há preocupação quanto aos relacionamentos amorosos, assim como as limitações profissionais impostas pela doença. Além da vontade de trabalhar para ajudar a família.

Quando eu for adulto eu queria ser bombeiro ou treinador de futebol. Eu queria mesmo é ser jogador [silêncio] mas eu não posso [silêncio e lágrimas nos ol hos] não posso jogar, não posso correr se não meu coração fica acelerado [...] Então eu preciso terminar a escola, preciso trabalhar e continuar tendo saúde. (C6)

Essas questões evidenciam o foco psico-social| ${ }^{11-12}$, que e importante, no entanto não contempla a transição da etapa do desenvolvimento da infância para adolescência que acontece permeado por essas interfaces do adoecimento decorrente da AIDS. 0 evento da soropositividade na vida da criança marca o cotidiano das idas e vindas à unidade de saúde, a medicação de sobrevivência, o sistemático e regular controle da carga viral e as mudanças nos hábitos de vida diária em comparação com outros adolescentes. A doença, o medicamento e a frequência às unidades de saúde marcam o diferencial na vida dessas crianças em transição para a adolescência.

Estudos já contemplam as situações vivenciadas no adolescer na contemporaneidade, como a gestação, as DST, o adoecimento por cardiopatia, diabetes, entre outras. Essas demandas do processo de saúde-doença culminaram em uma nova especialidade médica: a hebiatria.

No entanto, as crianças infectadas pelo HIV que estão transitando da infância para adolescência configuram um novo grupo populacional. São herdeiros de tecnologia medicamentosa, revelando-as como crianças com necessidades especiais de saúde (CRIANES). ${ }^{6-8}$

Esse grupo de crianças precisa ter visibilidade no quadro epidemiológico da pediatria e herbiatria. Além de serem conhecidas e compreendidas nas suas características, necessidades e possibilidades para serem cuidadas no processo de adolescer/adoecer. No entanto, pouco se sabe sobre o processo de adolescer com AIDS $^{13-14}$ em seus significados ${ }^{15}$, necessidades de tratamento ${ }^{5,16}$, inserção nos espaços sociais ${ }^{17-19}$ e assistenciais. $^{20}$

\section{CONCLUSÕES}

Como o foco do estudo incide sobre aqueles que foram infectados pelo HIV por transmissão vertical, associa-se o fato de que sua mãe também tem o HIV, e possivelmente o pai. Portanto, a criança e a família precisam de uma assistência à saúde especializada.

As contribuições da pesquisa consistem em dar visibilidade a este novo grupo de CRIANES em suas características biológicas e psico-sociais, suas necessidades diante do processo de transição da infância para adolescência e do processo saúde-doença pela AIDS.

Nos diferentes cenários de saúde, é preciso que as equipes que atendem essas crianças busquem resultados efetivos, como: um espaço específico para esse grupo de préadolescentes e adolescentes no serviço especializado; a capacitação dos profissionais para 


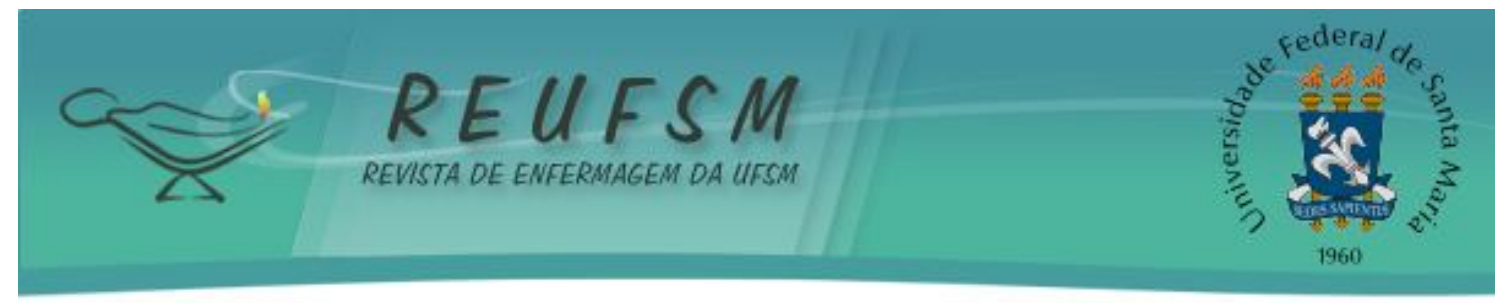

0 atendimento das demandas do processo de desenvolvimento e de adoecimento; a busca ativa das crianças/adolescentes faltosos nas consultas; o acompanhamento de saúde voltado para autonomia progressiva dos cuidados desenvolvidos pelas próprias crianças/adolescentes. Isso pode acontecer através do desenvolvimento e a implementação de uma política específica para esse grupo.

A promoção da saúde dessas crianças precisa contemplar: o acompanhamento do desenvolvimento e o acompanhamento das necessidades especiais de saúde. 0 primeiro inclui a atenção às demandas do crescimento e desenvolvimento puberal. 0 segundo envolve a atenção integral as crianças/ adolescentes e suas famílias no processo de adoecimento por AIDS, em suas demandas específicas, especialmente, a revelação do diagnóstico e a adesão ao tratamento.

Para o processo de revelação do diagnóstico é imprescindível o acolhimento o e aconselhamento da família quanto à importância da criança conhecer sua condição sorológica e ser incluída nas ações de cuidado com sua saúde. Após o momento de revelação propriamente dito, há a necessidade de manter 0 acompanhamento da criança/ adolescente e sua família para as repercussões dessa situação.

Para o processo de adesão ao tratamento, a educação em saúde pode ser uma estratégia para ajudar a criança a desenvolver progressivamente sua autonomia para cuidar de sua saúde.

Dentre a equipe multiprofissional, destacam-se as possibilidades de atuação da enfermagem, nos diferentes espaços sociais em que vivem as crianças que têm AIDS. No serviço de saúde, a enfermagem tem a consulta como estratégia de acompanhamento e intervenção junto à criança/ adolescente e às famílias ou cuidadores. A visita domiciliar pode ser outra estratégia de acompanhar a saúde dessas crianças e compreender sua situação sócio-econômica e seu cotidiano. Além de criar vínculo com as pessoas que cuidam das crianças e entender na prática como as próprias crianças estão comprometendo-se com seu processo de adolescer com AIDS e enfrentando as dificuldades do dia-a-dia.

A Enfermagem, também, pode atuar nas ações de prevenção nas escolas, ajudando as crianças a enfrentar as situações de (des)informação e preconceito no espaço escolar, inclusive, se aproximando e auxiliando os profissionais da educação na inclusão das crianças com AIDS.

Portanto, a pesquisa permitiu perceber que muitos são os desafios a serem enfrentados por essas crianças e suas famílias, mas com a atenção de uma equipe multiprofissional, e das ações possíveis à enfermagem, pode-se alcançar de modo compartilhado resultados efetivos na dimensão biológica e psico-social da vida das crianças que foram infectadas por transmissão vertical do HIV e que estão transitando da infância para a adolescência.

\section{REFERÊNCIAS}

1. Dourado I, Veras MASM, Barreira D, Brito AM. Tendência da epidemia da AIDS no Brasil após a terapia anti-retroviral. Rev saúde Pública. 2006; 40(supl):9-17.

2. Schaurich D, Coelho DF, Motta MGC. A cronicidade no processo saúde-doença: repensando a epidemia da AIDS após os anti-retrovirais. Rev enferm UERJ . 2006; 14(3):455-62.

3. França I Junior, Doring M, Stella IM. Crianças órfãs e vulneráveis pelo HIV no Brasil: onde estamos e para onde vamos? Rev saúde pública 2006; 40(supl):23-30.

4. Schaurich D, Medeiros HMF, Motta MGC. Vulnerabilidades no viver de crianças com AIDS. Revista enfermagem UERJ 2007; 15(2):284-90.

5. Gomes AMT, Cabral IE. O cuidado medicamentoso à criança com HIV: desafios e dilemas de familiares cuidadores. Rev bras enferm. 2009; 62(2):252-7.

6. Rezende JMM, Cabral IE. As condições de vida das crianças com necessidades especiais de saúde: determinantes da vulnerabilidade social na rede de cuidados em 


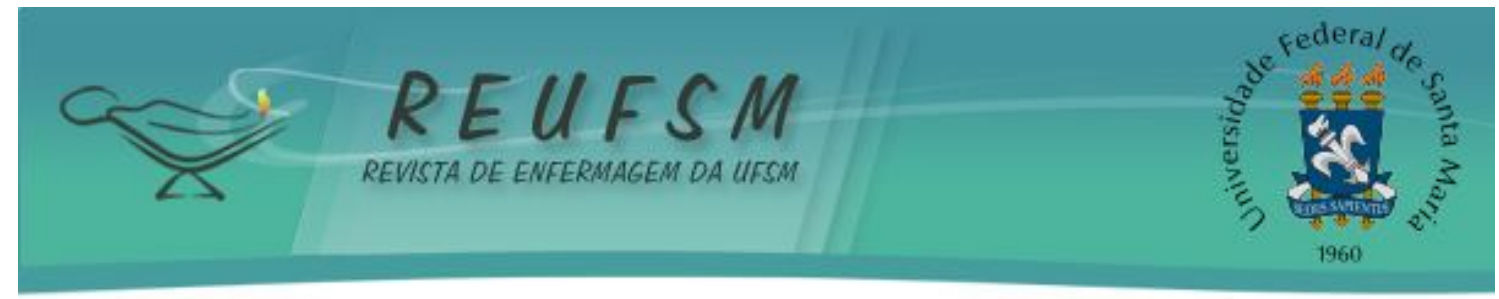

saúde. Rev pesqui cuid fundam. (online) [periódico na internet]. 2010 [acesso em 15 jun 2011];2(ed. supl. ):22-5. Disponível em: http:/ / www. seer.unirio.br/ index.php/ cuidad ofundamental/article/ view/773/ pdf_68.

7. Góes FGB, Cabral IE. Crianças com necessidades especiais de saúde e suas demandas de cuidados. Rev pesqui cuid fundam. (online) [periódico na internet]. 2010 [acesso em 15 jun 2011]; 2(2):889-901. Disponível em: http:/ / www. seer.unirio.br/ index.php/ cuidadofundamental/article/ view/579/pdf_22.

8. Silveira A, Neves ET. Crianças com necessidades especiais de saúde: tendências das pesquisas em enfermagem. Rev Enferm UFSM. 2011; 1(2):254-60.

9. Boemer MR. A condução de estudos segundo a metodologia de investigação fenomenológica. Rev latinoam enfermagem 1994; 2(1):83-94.

10. Bardin L. Análise de conteúdo. Lisboa: Edições 70; 2008.

11. Erikson EH. Identidade, juventude e crise. Rio de J aneiro: Zahar, 1972.

12. Erikson EH. O ciclo de vida completo. (versão ampliada) Porto Alegre: Artes Médicas, 1998.

13. Baricca AM. Vivendo e crescendo com HIV/AIDS. São Paulo, 2005. 136p.Tese (Doutorado) - Institutos de Pesquisa da Secretaria de Estado da Saúde de São Paulo, 2005.

14. Tavares MCT. A experiência de adolescer com AIDS. Belo Horizonte, 2001. 121p. Dissertação (Mestrado) - Universidade Federal de Minas Gerais; 2001.

15. Souza IAA. Adolescência e soropositividade: sentidos/significado do (con)viver enquanto portador do vírus HIV. Curitiba, 2003. 215 p. Dissertação (Mestrado) Universidade Federal do Paraná, 2003.

16. Ferreira FGF. Determinantes da adesão a terapia anti-retroviral em crianças infectadas pelo HIV. Belo Horizonte, 2004. 120 p.Dissertação (Mestrado) - Universidade Federal de Minas Gerais, 2004.

17. Lima AMA. O adolescer como portadora de HIV/ AIDS: um estudo com adolescentes e suas cuidadoras-familiares. Porto Alegre, 2006. 78 p.Dissertação (Mestrado) - Universidade Federal do Rio Grande do Sul, 2006.

18. Tomaz TB. Avaliação da proteção social a população infanto-juvenil: um estudo a partir das crianças e adolescentes com HIV e AIDS. J oão Pessoa, 2003. 150 p. Dissertação (Mestrado) - Universidade Federal da Paraíba, 2003.

19. Cruz EF. Espelhos d'AIDS: infâncias e adolescências nas tessituras da AIDS Campinas, 2005. 257 p.Tese (Doutorado) - Universidade Estadual de Campinas, 2005.

20. Ayres JRCM et al. Adolescentes e jovens vivendo com HIV/AIDS: cuidado e promoção da saúde no cotidiano da equipe multiprofissional. AIDS Novos Horizontes. edição especial Enhancing Care Initiative. São Paulo: Office Editora e Publicidade, 2004.

Data de recebimento: 22/06/2011

Data de aceite: 13/09/2011

Contato com autor responsável: Cristiane Cardoso de Paula

Endereço postal: Av. Roraima, s/ n, prédio 26, sala 1336. Cidade Universitária, bairro

Camobi, Santa Maria, RS. CEP: 97105-900.

E-mail: cris_depaula1@hotmail.com 